\title{
Universities and the Knowledge Economy
}

Citation for published version (APA):

Cowan, R. (2005). Universities and the Knowledge Economy. UNU-MERIT, Maastricht Economic and Social Research and Training Centre on Innovation and Technology. MERIT-Infonomics Research Memorandum Series No. 027 https://doi.org/10.26481/umamer.2005027

Document status and date:

Published: 01/01/2005

DOI:

10.26481/umamer.2005027

Document Version:

Publisher's PDF, also known as Version of record

\section{Please check the document version of this publication:}

- A submitted manuscript is the version of the article upon submission and before peer-review. There can be important differences between the submitted version and the official published version of record.

People interested in the research are advised to contact the author for the final version of the publication, or visit the DOI to the publisher's website.

- The final author version and the galley proof are versions of the publication after peer review.

- The final published version features the final layout of the paper including the volume, issue and page numbers.

Link to publication

\footnotetext{
General rights rights.

- You may freely distribute the URL identifying the publication in the public portal. please follow below link for the End User Agreement:

www.umlib.nl/taverne-license

Take down policy

If you believe that this document breaches copyright please contact us at:

repository@maastrichtuniversity.nl

providing details and we will investigate your claim.
}

Copyright and moral rights for the publications made accessible in the public portal are retained by the authors and/or other copyright owners and it is a condition of accessing publications that users recognise and abide by the legal requirements associated with these

- Users may download and print one copy of any publication from the public portal for the purpose of private study or research.

- You may not further distribute the material or use it for any profit-making activity or commercial gain

If the publication is distributed under the terms of Article $25 \mathrm{fa}$ of the Dutch Copyright Act, indicated by the "Taverne" license above, 


\section{MERIT-Infonomics Research Memorandum series}

\section{Universities and the Knowledge Economy}

\section{Robin Cowan}

\section{5-027}

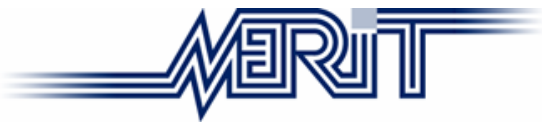

MERIT - Maastricht Economic Research Institute on Innovation and Technology

PO Box 616

6200 MD Maastricht

The Netherlands

T: +31433883875

F: +31433884905

http://www.merit.unimaas.nl

e-mail:secr-merit@merit.unimaas.nl

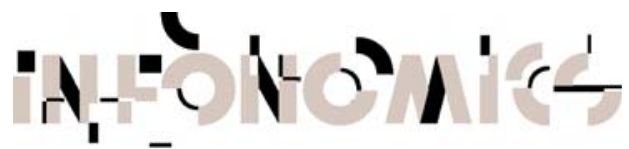

International Institute of Infonomics

c/o Maastricht University

PO Box 616

6200 MD Maastricht

The Netherlands

$\mathrm{T}:+31433883875$

F: +31453884905

http://www.infonomics.nl

e-mail: secr@infonomics.nl 


\title{
Universities and the Knowledge Economy
}

\author{
Robin Cowan \\ MERIT \\ University of Maastricht \\ P.B. 616 \\ MD 6200 Maastricht \\ Netherlands \\ r.cowan@merit.unimaas.nl
}

Paper prepared for the conference Advancing Knowledge and the Knowledge Economy at the National Academies, Washington, DC, 10-11 January 2005.

I wish to acknowledge many useful conversations with William Cowan during the preparation of this paper. The contributions of the Blueland Library should also be acknowledged. 


\section{Introduction}

The simplest rationale for the existence of a publicly funded university is that it provides some form of public good. If all the outputs of a university were privately owned, and privately appropriable, there would be no need for public funding. Either firms would fund the research and training which could be internalized by themselves, or students could fund the teaching through higher future earnings. Consequently, one way to pose the issue of the future role of universities is to ask what public goods they can provide that cannot be provided in other ways.

There are many possible types of answers to this question, and different answers receive emphasis at different moments in history. Over most of the modern period, though, we can observe one function of the universities that has been dominant, and ongoing, lasting until some time in the twentieth century. In The University in Ruins, Bill Readings coins the phrase "the university of culture". Readings argues that the modern university system builds directly on the writings of Humbolt and the German Idealists who were very explicit about the social role of the university. The argument is that universities are uniquely placed to provide a sense of national culture. By studying and teaching the social and cultural history of a nation, this culture is extended through time. Where this is valuable, and how we can see this as a public good, is in the way it conditions the citizens of a nation. The teaching function of this university creates graduates who are all steeped in the same cultural tradition, at least within one nation-state. They have a common view regarding their social and cultural roots; they share a world view; if the university is working well, the graduates fit well into the existing society, and can further its aims in the future. All of this has clear advantages socially, administratively and economically. In this tradition of course, the humanities take a central place in the university structure, as they are the repository of social culture that is so important in this sort of cultural extension.

Historically, this has been extremely important, and is very apparent in the German case. To create a single nation out of a collection of provinces, it is necessary to create a national identity to which all citizens can relate. Without this common view, or social 
bond, there is no reason that citizens of one province will feel any obligation or allegiance to citizens of any other. Without this, a nation cannot exist. To this end, a "tradition" must be created, or found, and expounded, and to the extent that all students are taught or exposed to the same tradition, an identity will emerge. If this identity is strong, graduates will be "good citizens", able to function well, achieve their ends, and still contribute effectively to the greater good. In the European context, within a nation (with some obvious exceptions) by and large this tradition has been a tradition of a literature, written in a particular language. Literature is social commentary, description or analysis, and the literature of one language provides the basis of description of a single culture. ${ }^{1}$

One can see a parallel here, as Readings points out, between the university of culture and a national airline. Until recently, Air France has probably been the best remaining example. Why does Air France still exist? Definitely not because it has produced great financial profits for its owners. ${ }^{2}$ Air France still exists (as is the case with so many French institutions) as an extension of French culture. Externally, it shows French technological prowess; French styles of service; French cuisine (perhaps). It is a means of projecting the French presence, and here this must mean cultural presence, since as an economic endeavour it cannot be said to be an unqualified success. Within France, it plays a closely related role. "Projecting" is not quite the right word in the internal context, but perhaps "advertising" is. Air France serves to remind the French citizen of French technological prowess and so on, as it does to the outside world. But in addition, it serves as a vital means by which all French citizens are linked to all others. It is a tool of cohesion. Flying unprofitable internal routes does not pay for Air France the company, but it does pay for Air France the promoter of French culture. And here is the public good that has been considered so valuable. The value this provides is to bind the French together (in a very old-fashioned way) which provides benefits throughout the society and polity, and, it is crucial to point out, to other French industries. On the latter point, consider the "irrational" loyalty the French have to their wine industry. (Though to be fair, one does occasionally hear a French citizen admit that there might be one or two Italian wines worth drinking.) And because this public good is considered so valuable, Air France has been protected for the economic sphere. Just as, historically, the universities have been.

The university of culture did provide economic benefits, through creating a cadre of administrators who shared a coherent view of the world, and so were able to create policy

1. Philosophy is the other discipline that looms large in this university, as it is a discipline that explicitly examines "how to live", which is clearly a central question in the "soul" of a culture.

2. The situation of Air France has changed since 1993 when it received a 2 billion pound subsidy from the French government: it no longer enjoys this sort of protection. 
with at least an over-arching coherence, and it created a cadre of managers whose view fit well with that of the policy makers. The most explicit exemplar here are the French (again) Grandes Ecoles, which have provided generation after generation of administrators and managers who all had a common goal (the furtherance of French prestige, roughly speaking) and common views both about the value of that goal and about how to achieve it in the broadest senses. But this is all clearly a public good. It is a benefit that is not appropriable by any single agent or even group of agents. Consequently, the university has been publicly funded, and protected from the economic sphere. It is very important to notice one other thing in this respect, which is that while the state was funding the university, it was the university that was defining the nation or state, and not vice versa. The university itself studied, and thereby defined the culture that was being promulgated, but it also determined how that promulgation took place. Those funding the university had a minimal role in directing it. This independence between the funding and the details of the activities has been extremely important for the system as a whole.

This is a description of the universities until sometime in the middle of the twentieth century. But since then, the university of culture has been disintegrating. The role of the university is no longer to provide the next generation of good citizens. Part of the reason is that this role builds and is built upon, a relatively strong presence of nation-states. But as internationalization proceeds apace, the place of the nation-state recedes. We see this economically in the rise of the trans-national corporation which have become of the size of nations, and in international currency flows which are of the size of the GDP of nations. We see this socially through large international migrations. And we see this in the universities, particularly obviously in the "culture wars", in which violent arguments, particularly in the English-speaking world, erupted about the definition of the culture we are studying. Fights over tradition and canon were essentially about the definition of "the culture", and the existence of these fights indicates that the existence of a culture that defines a nation can no longer be taken for granted. The university of culture is no more.

There is an irony worth pointing out. One of the effects of the university of culture was to facilitate and even drive a growth in national cohesion, which was particularly visible in Germany. Different regions within a nation, by exposure to the common cultural tradition that was developed and promulgated through the national university system, slowly converged, at least in their views of the cultural traditions. This opened the possibility for, and indeed helped to create a form of national "social cohesion". That phrase, "social cohesion" is used deliberately, and anyone familiar with European Commission Framework Programme documents, and even some of their tender documents, will rec- 
ognize it. One of the big issues within the Commission is creating cohesion across the different regions in Europe. As part of the published evaluation criteria for Framework proposals, the contribution of the proposed project to social cohesion looms large. Just when potentially a new role, in Europe at least, for the university of culture emerges, the university of culture disappears.

So if the old role for the university has gone, and old university structures are crumbling, what exists now, or what will rise to take its place?

At this point I depart from Bill Readings and pursue a different tack. Readings view, which seems quite perceptive to me, is that we are now living in the University of Excellence, and he has insightful things to say about what that means. ${ }^{1}$ But I am going to turn to innovation and innovation systems.

\section{The linear model abdux ${ }^{2}$}

In the bad old days innovation was viewed as a linear process, and was described using "the linear model". The general idea was that basic R\&D provides the foundational knowledge for applied $R \& D$, which provides the foundational knowledge for innovation, which then becomes a good to be diffused to users. The process is linear, with one stage feeding the next, and it is uni-directional. On this model, the role of universities was clear. It was to do the basic R\&D, thereby providing the foundational knowledge, information, data, instrumentation and so on, on which the entire rest of the innovation edifice is built. In terms of public goods, the role is also clear. Knowledge is a public good (Arrow, 1962; Nelson, 1959) and so basic R\&D, being the most widely applicable of all types of knowledge, will be severely under-supplied by the market. Problems of extensibility and appropriation will deter firms from producing this type of knowledge. Given its importance to the entire system, it had better be provided publicly. This is a very nice, simple model, in which it is relatively easy to see the roles played by different actors and institutions, and it has clear implications for research funding. As we proceed from basic R\&D to diffusion,

1. One of the amusing things that Readings points out is that if you look at the public web pages of universities you discover that they all describe themselves as unique. Interestingly, they are all unique in exactly the same way: they are excellent. What it means to be excellent exactly is anyone's guess, and is pretty much up for grabs.

2. The history that follows here, while not a fiction, is meant to be rhetorical, rather than a detailed account of the history of thought in the economics of innovation. For that, see for example Rothwell (1992). 
the outputs become more and more appropriable, so there is less and less need for public subsidy.

While the model has these desirable properties, it was also seen as having one or two problematic aspects. First, it was difficult to find examples in which "pure" basic research led directly to products (see for example Rosenberg, 1982, chapter 7), though nylon and the laser are two favourites. Second, it was easy to find examples where most of the innovations in an industry were made by the users, involving very little, if any, science at all (see von Hippel, 1976, 1977, 1986). The first observation makes us wonder what basic $\mathrm{R} \& \mathrm{D}$ is really doing in the context of an innovation system. The second observation implies that in our model we need a feedback, a way for users to be putting information into the process, rather than just using the outputs of it. So to our simple structure we should add a link, or more than one, in which users are connected to other players, providing them with information or knowledge inputs for their activities. But once you start adding feedbacks to a model, any model, the temptation to add "just one more" it is hard to resist. And soon emerged the system model of innovation.

The system model of innovation, sometimes known as the National Innovation Systems model, emphasizes that there are many different types of actors or institutions which contribute information or knowledge to the innovation process, and that information flows in many directions between many different types of agents. In the this model, many agents matter, and they matter in many ways. But if we say, with just a little bit of exaggeration, that when thinking about innovation "everything matters", it is quite natural to ask, "Does anything matter more than anything else?", or "Does everything, as input, matter for everything, as output?" One could argue that the system model of innovation has seriously over-corrected the faults of the linear model.

But be that as it may, we can still sensibly ask, if universities are part of the innovation system what is their role within it? There is an obvious, and uncontroversial answer, namely that the universities provide highly trained graduates. (If this is all they do, then probably they should be transformed into vocational schools.) But if universities are linked in many ways to many different entities in the system, surely they contribute in other ways as well. The natural answer in its general form, is clearly that universities are a source of knowledge and information (after all those are the main products of research) on which other entities can build market-valued goods and services. And in this regard the systems model is very similar to the linear model. Where it differs in a very important way is that in the system model the university can take in knowledge and information from many different sources. In the original linear model by contrast, it appeared as if knowledge was 
generated in the universities without any inputs from the outside. In this regard, the systems model was a much better representation of university research (of which more below). But pushing hard the line that universities are a source of knowledge an information for other actors, the justification of the university system becomes the applicable knowledge it feeds to innovators.

In recent years, there has been considerable interest in what are called the sciencebased industries. Biotechnology is the most prominent example. The claim is that innovation and output in these industries depends heavily on very recent advances in (university) basic research, and thus they provide the paradigm example of how universities contribute to the innovation system. We see concern in policy-making circles, particularly in Europe, to extend this vision to other industries as well. ${ }^{1}$ While this vision may apply to some industries, ${ }^{2}$ it is important not to let the biotech tail wag the innovation system dog.

Asking this question, and asserting as part of the answer that universities have a crucial role, invites difficulties for the justification of public support for the university. The reason is that by making a claim that universities are important players in a system of innovation, we are implicitly making the claim that the university has an economic role, and thus its support can be justified by economic arguments. By emphasising that universities play this role we move away from the cultural or social justification of the university, arguing that it makes a strong contribution to wealth generation, and over time, the contribution seems to be, in the arguments at least, more and more direct. We are inviting the removal of the protection of universities from the economic sphere. And indeed, we are getting what we asked for. ${ }^{3}$

The Bayh-Dole act is a perfect manifestation of the view that universities can contribute very directly to wealth generation. The idea that there are lots of patentable, and

1. For evidence of just how much this is troubling EU policy makers, see the proceedings of the conference The Europe of Knowledge 2020: A vision for university-based research and innovation, Liege, April, 2004, in which an ever-present theme is how the university system will support innovation in various industries and sectors in the coming decades. http://europa.eu.int/comm/ research/conferences/2004/univ/index_en.html

2. Though one is tempted to ask why biotech is not able to do the research in-house, merely by hiring professors at large multiples of their academic salaries. Could it be that what biotech is buying is not knowledge or research, but rather "independence" with which to impress regulators? But perhaps such cynicism is best left undeveloped.

3. This rhetoric is certainly unfair, in that it reads as if the purveyors of the systems model of innovation must take the credit or blame for the ongoing push towards the market. It is quite possible that this is a case rather, of seeing which way the wind is blowing, and bending with it. 
therefore marketable and economically valuable ideas lying around on lab benches makes the university contribution to wealth creation almost as direct as it is possible to be.

As central players in the innovation system universities provide inventions (which they should patent, as a means of improving technology transfer from university to industry), instrumentation, which is necessary for doing further, and probably more applied, research, and they are providers of skilled labour, which industry can employ in its own innovation activities. All of these are relatively direct contributions to the economy in general, and to innovation in particular. The justification of the university here is as a creator of wealth, if indirectly. But where is the public good? Technology transfer via the patent system is by definition not a public good. The public good aspect remains the conventional one: the outputs of teaching and basic research.

\section{The linear model redux}

I want to propose that perhaps there is a simpler change to the linear model which, while retaining its simplicity, addresses the two problems mentioned above, and will lead to a slightly different view of the university's role. ${ }^{1}$ It would remain a very stark model, missing many features of an innovation system, but in its starkness and simplicity, it does permit a certain focus, which can be difficult to obtain with more complex models. What I want to propose is simply moving basic R\&D to the end, rather than the beginning of the process, and then adding a feedback, from the end to the beginning.

The ivory tower is not a windowless edifice. Scientists do look out its windows from time to time, and what they see affects what they consider to be interesting problems. Peter Galison (2003) discusses the development of Einstein's theories of relativity, and Einstein's concern with time and how we could know that events located at two distant points in space happen at the same time. Galison argues that it is no coincidence that Einstein was working on this at the moment at which railroads and cities (in Switzerland, and Bern, near the patent office in particular) were developing technologies to coordinate their clocks. It is also no coincidence that Poincaré was working on virtually the same problem, independently of Einstein, just a few years earlier. He was, after all, in the Paris Bureau of Longitude, for which one of the major challenges of the time was to find a way for sail-

1. I don't mean, here, to suggest that the system model is wrong. There are typically many "right" models of any given phenomenon. Models are made, not found, which means that given that several right models can be constructed, the interesting issue becomes which one is most useful in the circumstances. 
ors to determine Paris time from anywhere in the world, so they could effectively measure the longitude at their own location. Poincaré did not get to relativity, but his central concern was the same as Einstein's initial concern, namely what "simultaneity" means. Here we see an example of some extremely theoretical basic research which was closely connected in inspiration at the least to developments in technology. This position more generally, that science is not isolated from the "real world", in a windowless ivory tower, is central in recent sociology of science (see Barnes et al.,1996, for example for a recent text). While it is true that the fundamental quest for science is the truth, there are very many possible true statements or facts that could be pursued. ${ }^{1}$ Why this one rather than that one? How do scientists decide what to investigate? In part at least, the answer is driven by the things they observe in the world, whether it is technological developments, new industrial processes, or economic phenomena.

Rosenberg (1982, especially ch. 7) argues that a typical pattern is that basic research follows technological or applied developments. The relationship between science and technology is complex (certainly moreso than my simple revision of the linear model would allow) but it is common that basic research serves to provide the theoretical explanations of things that are already being used in practice. Phenomena observed in practice, whether puzzling or just interesting, prompt scientists to look for the underlying physical processes that explain them. ${ }^{2}$ Sometimes the phenomena are existing technological successes which can be understood at a more general level; sometimes they are existing technological problems in the solving of which basic results are produced. In either case, though, the direction of scientific or basic research is strongly affected by existing technological products. A big part of basic research picks up phenomena in the outside world, sometimes natural, often man-made, and tries to explain them by asking about their fundamental underlying principles.

This seems like a rather pessimistic view of university research. University scientists here lag bebind the "real world", instead of leading it, and even so, they continue to engage

1. One can remain agnostic on the debate between realism and instrumentalism while making this claim, simply observing that even if "truth" is defined differently under the two views of the scientific enterprise (and even if some instrumentalists avoid the word "truth" altogether) searching for it remains an objective regardless of the outcome of this debate. On these issues see Putnam (1990 for example).

2. Some of Rosenberg's examples: short-wave radio transmission and properties of the ionosphere; short circuits and whisker crystals; the properties of Bessemer and post-Bessemer produced metals and metallurgy; aluminium alloys and "age hardening"; petroleum cracking and the general effects of heat on hydrocarbons; semi-conductor use and semi-conductor theory. 
in navel gazing. Now their connection to the outside world is purely that it serves as a source of navel lint.

But this interpretation is overly pessimistic, and misses one very important aspect. A senior manager in charge of university relations at a major computer firm stated in conversation that his main goal in having professors visit his firm was try to raise their intellectual curiosity about the types of developments the firm was involved in. He was explicitly not trying to get them to solve his technical problems; he was trying to steer their (basic) research interests. The value of the involvement of academics in a firm is not in immediate product development, rather it lies in the future.

When a scientist does basic research, he or she is observing some phenomenon and making a model of it. With a model, it is possible to extract the important, central features and causal connections driving the phenomenon, and to understand "how it works". When the phenomenon is technological, as in several of Rosenberg's examples, it can involve the tacit knowledge of the practitioner. The process of basic research can be seen, by extension, as tantamount to a process of codification. ${ }^{1} \mathrm{~A}$ phenomenon or process is described in a compact, reproducible way in which its fundamental aspects are captured, and secondary or unimportant features are set aside. In a completely new field codification involves developing a vocabulary, models and a language in which the phenomena can be described. Depending on whether the phenomenon fits into an existing field or is entirely new, different activities receive more or less attention in this process, but all of them are central to the abiility to teach the principles that are discovered.

What is being codified, typically, in the research process, is a causal structure that explains some phenomenon. A phenomenon is typically broken into several pieces, and then the pieces are linked. The research activity must decide first, what to consider as "a piece". There are a huge number of ways in which any thing can be partitioned, and the partitioning into constituent components is utterly central to the enterprise. Then, of course, the issue is how those pieces fit together, causally, to explain the observed effect. ${ }^{2}$ The reason I emphasize this has to do with causation. This is a tricky idea and many attempts, beginning with Aristotle, have been made to provide a theory of it. One such attempt seeks to connect the idea of causation with the idea of "control" or manipulability. ${ }^{3}$ That is, understanding the causes of a phenomenon implies understanding in principle

1. See Cowan and Foray (1997) or Cowan et al. (2000) on the economics and process of codification.

2. Obviously, the partitioning and causal connection building are not independent activities.

3. See for example Collingwood (1940), Gasking (1955) or Menzies and Price (1993); or for a version less dependent on human intervention, Pearl (2000). 
how to control it. While this remains a view that has some difficulties to be addressed, the central idea indicates how basic research can be a powerful input into innovation. Innovators are centrally interested in how to control processes. It is new-found control over phenomena of that permits them to produce new products and processes. So causal models are indeed inputs to the innovation process, but, as Rosenberg and von Hippel would argue, not as direct as this paragraph seems to suggest.

The route I will suggest comes through teaching. Once a phenomenon is understood; once a causal model that explains it exists and has been codified, it can be taught. The role of basic research is as an input to teaching. It permits universities to create graduates who understand, at a relatively deep level, technologies, phenomena, processes that have already been observed or created. That is, today's graduates understand yesterday's innovations. And they understand them not only in the purely pragmatic way that interests the entrepreneur (if I do X, there is an effect $Y$, which can be translated into higher productivity or better product), but they also understand why $\mathrm{X}$ produces $\mathrm{Y}$. They are not taught, and this is important to acknowledge, how to turn $\mathrm{Y}$ into higher profits. This is an extremely important difference between an entrepreneur and a scientist. Scientists are attracted or driven by "interesting phenomena" and not by "interesting market opportunities". ${ }^{1}$ This observation of the difference between academics and entrepreneurs constitutes a strong reason for scepticism regarding the view that universities can be a source of directly applicable knowledge for innovators.

The fact that today's graduates understand yesterday's innovations is not the problem it sounds like, since today's graduates, or at least those of them who escape the university, will be tomorrow's innovators. Their innovations will build on their knowledge, and their understanding of how things work. This is the reason it may be more apposite to speak of highly qualified rather than highly trained personnel, as the latter implies a strong degree of vocational skills, while the former connotes a heavier emphasis on general skills. The ability to be a successful innovator depends on levels of general understanding, that is, the understanding that comes from the outputs of basic research. But again it is worth emphasising that the results students are being taught are not of the "with a little refinement this theorem will become a product" variety. It is far more general than that.

The conclusion here is disappointingly conventional. The role of universities is to couple research and teaching. The output is highly qualified personnel. The human capital embodied in graduates is not highly specific, and is in fact general enough that it con-

1. This can be interpreted as one of the reasons why the technology-push model was replaced by the demand-pull model, to use Rothwell's (1992) terminology. 
stitutes a public good, or at least without labour contracts that are tantamount to indentured servitude, a non-appropriable good.

\section{Innovation ignored}

Is there something beyond this disappointingly conventional conclusion about the place of the university? Does the university do more than simply analyse today's phenomena and teach the results of that analysis to tomorrow's innovators? I believe the answer is yes, or at least has been yes, but that the recent emphasis given to the university as a player in the innovation system threatens that activity.

The activity I refer to is "reflection". The university is the only place in modern society in which non-teleological reflection is institutionalized. Part of the role of the university has been to provide a location in which members of the society could reflect on what the society is doing, to discuss any issue thought pressing, without reference to any outside constraints or goals. It provided a place for thought that was insulated both from the political process and from the market. It was a place in which the phrase "Let's stop and think." was a sort of a trump card. Any issue can be worthy of careful, deliberate, unrushed discussion and analysis, and the university was a place in which this activity was revered. This idea, that somewhere, someone should be able to resist any pressures to treat an issue either quickly, or with a particular frame of reference, or even with a particular outcome in mind, was considered a fundamental part of a well-functioning society, and was built into the university ethos.

What goes hand in hand with this is a concern for truth. In the university setting, in principle, the truth trumps everything. When faced with a choice between action motivated by truth, either seeking it or acting upon it, and action driven by some other motive, the former is lexicographically preferred. Obviously, people can be mistaken about the truth, believing things that are not in fact true. But within the university setting, this is not an issue. Pursuit of, and statements about beliefs of truth are meant to be the dominant currency. There is no other institution in society in which this is the case. ${ }^{1}$ And it seems patently obvious to me at least, that this is a valuable function.

1. One might make a claim that the monasteries perform or did perform this function. As such they bear similarities to universities: one could argue that monestaries were the preserve of those who glorify the god Yahweh, whereas universities are the preserve of those who glorify their own god, namely consistency. 
But the insertion of the university into the innovation system, and thereby into the market sphere is seriously threatening this role. It introduces a second, and growingly important, criterion on desideratum for action, namely the economic effects or value of it. If a university is passing things to the "outside world" it must be aware of what its "clients" want, and at some level, deliver it to them. This has always been true to some extent, even in Readings' University of Culture, since there the universities were delivering a social cohesion which the state (funding the universities) wanted. But notice that this is a demand specified in very general terms, and in fact the universities determined the details of how and what was delivered. When the demands becomes more specific, clients have a louder voice in the what and how.

The pressure of the market means that even that most "ethereal" of departments, namely philosophy, is now offering courses to appeal to the market, for example in medical ethics. One could make the case that this is not necessarily bad, and that many people outside academe need now to be able to think carefully and effectively about such issues, so this pressure on philosophy departments could constitute a very important contribution to society. But there are other cases which cannot be explained away like this. They are emblematic, it seems, of the thought that the market has no interest whatsoever, except possibly instrumentally, in the truth. Two recent high publicity cases at the University of Toronto make the point. In the year 2000, David Healy was appointed as the Professor of Psychiatry and Head of the Mood and Anxiety Disorders Program within CAMH (Center for Addiction and Mental Health). The offer was formally made and accepted. In August, he gave a lecture in Toronto in which he discussed, among other things, the idea that serotonin re-uptake inhibitors could contribute to suicidal tendencies. This was not a new idea of his, he had published papers and lectured on it many times in the past. Within days, his appointment was rescinded. Of course no one knows exactly why this was done, so it may just be a coincidence that half ${ }^{1}$ of the funding of the mood disorders program at CAMH came from pharmaceutical companies. ${ }^{2}$

The second case in Toronto involved Dr. Nancy Olivieri, former head of the Sick Children's Hospital's haemoglobinopathy programme. Her research on the drug deferiprone showed up unexpected side-effects, so she decided to break a confidentiality

1. As reported by the Canadian Broadcasting Corporation.

2. In a similar, earlier case, Healy had written an article published by the Hastings Institute, in which he warned of possible problems with SSRIs, and produced evidence that an increasing proportion of the therapeutics literature was ghost-written (Healy 2000). It turned out that Lilly was one of the biggest private funders of the Hastings Center and following this article they withdrew their support. For more on these cases see http://www.healyprozac.com/AcademicFreedom/default.htm 
agreement with Apotex, the Toronto pharmaceutical company that was sponsoring her research, tell her patients, and publish the results in the Nerw England Journal of Medicine (Olivieri et al., 1998). She was subsequently threatened with legal action by Apotex, and what is more astonishing, removed from her hospital post by the university. Naturally, this caused quite a stir, but the report on the affair observed, among other things, that this lack of independence of researchers was no longer uncommon. In other (quite ugly) words, industry sponsors of research appear now to be attempting to buy the results they want, or at least suppress the results they don't want. ${ }^{1}$ And in doing so they seem to be able to dictate university policy. ${ }^{2}$

The ability to put truth at the head of the list of motivations, and the ability to pause and reflect, are both seriously threatened by the universities' having been pushed towards the market. What it points to is a very difficult issue. In order to protect these aspects of university culture, it must be the case that research (and indeed other university activity) is to a very great extent independent of funding sources. Of course this makes justification of university activity extremely difficult, since funders naturally ask, "What are we getting for our money?" and demand, "Show that our money is not being wasted". If funders feel they should have a loud voice in determining university activity, it is naturally quite easy for them to see waste, in activities that do not directly further their aims. If funding agencies, whether public or private, are assured that universities will make great contributions to an innovation system, and funding is based on this argument, then activities that do not respond directly to that goal, are waste. Activities that have the nature I have been describing in this section will almost automatically fall in this category.

\section{Conclusion}

I stated at the outset that universities have always provided some public good, and this was how they justified public support. On the model described by Humbolt, which survived through most of the modern period, universities provided a steady stream of "good citizens". Their value showed in their ability to administer the nation as a nation, integrate with existing enterprise to promote the national economy, and in their ability, and indeed affinity to support and further its cultural identity. Social cohesion was an important pub-

1. Olivieri was eventually reinstated to her post, and otherwise vindicated (Spurgeon, 1999).

2. It may only be coincidence that both of these cases involve medicine, and in particular pharmaceutical research. But if not, this may be another reason for fearing the biotech tail of the innovation dog. 
lic effect. In the early twentieth century, universities provided a large cadre of highly educated labour. On the back of this labour tremendous economic growth and social change was built. Again it was an output that due to its nature was non-appropriable. What is the public good of the future? I have argued above that again it is a body of highly qualified personnel. Again, as graduates they are not "trained" as they would be in a vocational school, but rather educated in the broad sense. Vocational training can in principle be made a club good, but education remains a public good, due to labour mobility. Adopting this model or view, especially in the European context, we open the door to the redistribution of human capital. If the labour mobility is across borders, so too is the redistribution. This will break down further the national identities that were such an important part of the German university model. On the other hand, it provides a route to create the Holy Grail of the EU Framework programmes, and possibly of the European project itself, namely "social cohesion". ${ }^{1}$ But notice that this does not follow the model of the University of Culture, in that the goal here is not to find some European literary tradition, or on the American model a literary canon, through which to create and then pass on a cultural tradition. One suspects that the cultures are too diverse. This suggests a shift from the humanities to the social sciences as the intellectual centre of the university. Here it may be possible to find more, broader-based cohesion.

In terms of "channelling knowledge" my argument seems to come to the following conclusions. The systems model was right: knowledge does flow into the university research environment. It does so by scientists observing interesting phenomena, and asking how they work. Industry can provide a lot of this observation, and in doing so, interest the university scientist in phenomena that industry perhaps uses, but does not understand. But this is definitely not a new way of saying that universities can solve problems that industry is having. Rather, universities are codifying things that industry either does not understand, or only knows tacitly. Here is the public good, which does serve to help the innovation system, though in a very general way: the university produces basic, public knowledge, and a stream of graduates who understand it.

Where does this leave reflection and truth? On this model of the university's role, they are restored to, or perhaps supported in their rightful place. Because industry, or the

1. The Commission does seem to be aware of this. It is actively trying to foment social cohesion through universities and research institutes. This is most obvious at the level of the (senior) researcher, through Framework Programme evaluation procedures, but it exists as well at the level of graduate students and post-docs through various Marie Curie activities. It is very much weaker at the undergraduate level, which is probably the most important level of the three. But perhaps the Bologna Accord is a step in that direction. 
external innovation system in general is not a "client" of the university, the latter does not need to produce something that industry wants to buy. The question "What is the market value of this activity?" again recedes in the university sphere, and can be replaced by "Is it true? Let's stop and think." 


\section{References}

Arrow, K. J. (1962) "Economic Welfare and the Allocation of Resources for Innovation", in: The Rate and Direction of Technical Change, R. Nelson, (Ed.), New York, National Bureau of Economic Research.

Barnes, B., Bloor, D, and J. Henry (1996) Scientific Knowledge: A sociological analysis, Chicago, Chicago University Press.

Collingwood, R. (1940) An Essay on Metaphysics. Oxford: Clarendon Press.

Cowan, R., P. David and D. Foray (2000) "The Explicit Economics of Knowledge Codification and Tacitness" Industrial and Corporate Change, vol. 9(2): 211-253.

Cowan, R. and D. Foray (1997) "The Economics of Codification and the Diffusion of Knowledge", Industrial and Corporate Change, vol. 6: 595-622.

Galison, P. (2003) Einstein's Clocks, Poincarés Maps: Empires of Time, New York, Norton.

Gasking, D. (1955) “Causation and Recipes”, Mind, 64, pp. 479-487.

Healy, D. (2000). "Good Science or Good Business?” Hastings Center Report 30: 19-22

Menzies, P. and Price, H. (1993) "Causation as a Secondary Quality", British Journal for the Philosophy of Science, 44: 187-203.

Nelson, R. (1959) “The Simple Economics of Basic Research.” Journal of Political Economy 67:297-306.

Olivieri N.F., G.M. Brittenham, C.E. McLaren, D.M. Templeton, R.G. Cameron, R.A. McClelland, A.D. Burt, K.A. Fleming (1998) "Long-term safety and effectiveness of iron-chelation therapy with deferiprone for thalassemia major" New England Journal of Medicine. vol. 339(7):417-23.

Pearl, J. (2000) Causality. New York: Cambridge University Press, New York.

Putnam, H. (1990) Realism with a Human Face, Cambridge MA, Harvard University Press.

Readings, B. (1996) The University in Ruins, Cambridge, Harvard University Press.

Rosenberg, N. (1982) Inside the Black Box: Technology and Economics, Cambridge, Cambridge University Press.

Rothwell, R. (1992) "Successful industrial innovation: critical factors for the 1990s", R\&D Management, vol. 22(3).

David Spurgeon (1999) “Toronto research funding dispute” BMJ vol. 318:351.

von Hippel, E. (1976) "The Dominant Role of Users in the Scientific Instrument Innovation Process," Research Policy 5(3): 212-39.

von Hippel, E. (1977) "The Dominant Role of the User in Semiconductor and Electronic Subassembly Process Innovation," IEEE Transactions on Engineering Management $\mathrm{EM}-24(2):$ 60-71.

Von Hippel, E. (1986) “Lead users: A source of novel product concepts," Management Science 32: 791-806. 
